\title{
Evaluating Social Innovation Tools: Process-Oriented Approach
}

\author{
GABRIELLA METSZOSY \\ PHD STUDENT \\ UNIVERSITY OF MISKOLC \\ e-mail: szvmg@uni-miskolc.hu
}

\begin{abstract}
SUMMARY
The aim of this paper to analyse the success factors of efficiency of social innovation and indicate the variables associated with the success factors in order to aid in decision making A number of success factors play an important part in adjusting to reach the optimal solution. The personality of the innovator, level of the innovation or the place of implementation can influence the choice and prioritizing of these factors. Identifying the forms and level of decisions in connection with success factors is the main focus of the paper, determining the presence of linked variables. A suggestion is formulated to increase the efficiency of decision making taking into consideration the applied decision methods and special features of the situation.
\end{abstract}

Keywords: social innovation, process-oriented framework, decision support

Journal of Economic Literature (JEL) codes: D83, O35

DOI: http://dx.doi.org/10.18096/TMP.2020.01.03

\section{INTRODUCTION}

Various types of conceptual framing are becoming identifiable regarding innovation. This general phenomenon emerges from the impossibility of exact interpretation. Innovation is impossible to describe as a simple process (Saad 2004). The definition of social innovation is not uniform; some definitions come from a development of the orthodox innovation definition, while in other cases an entirely new definition was created. Murray et al. (2010) described social innovation as innovation where the tools and goals are societal, new relationships or cooperation are created and social needs are being satisfied simultaneously. According to the European Commission description (2014), social innovation includes the ideas, models, products, and services which satisfy social needs and create new social interactions. The Centre for Social Innovation highlights the importance of supporting the social progress by providing solutions for social and environmental problems. New problems arise as time wears on, and the solutions for these problems are hardly manageable without the participation of social innovation. The difference between the common sense of innovation and social innovation is determinable by the difference in goals. The aim of social innovation activities is to improve people's well-being and decrease the disadvantages of the peripheral areas using different tools (Shantz, 2015).
Based on the literature (Zapf 1991; Simms 2006; Pol \& Ville 2009; Angelidou \& Psaltoglou, 2017; EdwardsSchachter \& Wallace 2017; Kocziszky et al. 2017; Misuraca \& Pasi, 2019;), it is possible to distinguish eight different areas of social innovation where the critical factors required different types of evaluation and consideration.

$>$ To do good for society: innovation for reaching defined social goals; new or novel, efficient and sustainable solution for social problems.

$>$ Changing the social structure: new configuration of social practices for a specific purpose.

> Changing social practices: new combination of social practices in a specific field or social contexts for better answers to social needs.

$>$ Contribution to regional or community development: reaching the community level progression (such as empowerment).

> Digital world, community presence in the innovation: possibilities are related to innovation in the digital connection of social network such as crowdsourcing or crowdfunding.

> Endowing different type of innovations with social importance: giving different types of attributes for type-specific innovations - such as technological innovations - which exert socially beneficial impact. 
$>$ Process reengineering: renewing and restructuring the intra-organizational processes in favour of more effective community work.

$>$ Social work: developing the sensitivity in favour of social work and developing the process of social work to reach the societal goals.

During the process of social innovation, differentiation among the types helps for choosing the right supporting tools.

\section{SOCIAL INNOVATION AND ITS INFLUENCING FACTORS}

The general steps of process illustrative of all types of social innovation can be described in eight steps (Sanders et al. 2007; Tohidi \& Jabbari 2012; Rajapathirana \& Hui 2018; Soma et al. 2018; Metszosy 2019):

$>$ Preparation: defining the territorial limits, scope and required basic knowledge for implementing social innovation. Mutual understanding is essential to describe the actions related to each phase, so applying the tools for shared thinking is required. Defining the goals is necessary for the continuous revision.

$>$ Specifying the directives: formulating the challenges related to goals and the developing area, defining the activity to be improved. Understanding the target group is necessary for the success, and adopting idea generation methods is useful tool for understanding the presented needs and determining potential solutions.

$>$ Conception: designing the expected outcome and feasibility, selecting conceptions. Evaluating sustainability with potential cooperatives using proper communication tools.

$>$ Prototyping: defining the value-adding elements and decreasing barriers. Analysing the current situation and carrying out a resource audit to specify or reformulate the goals.

> Sustainment: defining the strategy and achieving actions in small steps for longer sustainability. Continuous assessment is based on feedback and monitoring, which requires knowledge and relationship management.

$>$ Adjustment, measuring: measuring the performance of society and evaluating financial sources such as grants, donations, crowdfunding and benefits. Several types of financial indicators and statistical methods can be expedient.

> Systematic changes: mobilising participants for the development of a social movement.

$>$ Learning and developing: new knowledge development and knowledge transfer occur during the process as a result, and with a knowledge bank the information will be available for further processes of development.

The success of social innovation process is influenced by several factors which may carry variant weights in each phase and level of implementation. Most of the hard factors can be measured on the basis of existing data; its impact on implementation can be directly determined with different types of analysis such as sensitivity analysis. In contrast the soft factors are more difficult to measure and their impact is hardly detectable by direct means, although the weights of these are important in the process.

In order to evaluate the process of social innovation at different levels, defining the indicators is necessary to measure the effect of each phase and applying different approaches for decision support. Various characteristics include quality, satisfaction, acceptance, understanding and cost reduction, which can all be measurable variables during the assessment (Kaderabkova \& Saman 2013). It is noticeable that various success factors were identified in connected to different types of social innovation. Success factors cover a limited number of areas where satisfactory results ensure the improvement of well-being through the success of process (Rockart 1979). A Success factors approach allows us to focus on critical decisions of process, because achieving goals is highly dependent on proper and accurate evaluation of success factors (Anand et al. 2009). Based on my systematic literature review, the most cited success factors are:

$>$ Collaboration, integration: should include individuals, organizations and communities involved in the action in any way. Lack of support and common thinking are impediments during implementation, so an openminded, innovative approach, empathy and patience are needed to conduct the process (1).

$>$ Culture: being part of a social innovation action requires different attitudes and routines in comparison to everyday work or volunteering. Different values and attitudes are necessary to support the confidence and commitment in an underprivileged community; the results of social innovation are not developed at once in most cases. Maintaining the community cohesion is essential for developing the supporting culture (2).

$>$ Experience: successful earlier activity by the innovator or participants. Previous experience helps to determine the way to develop the necessary knowledge and reduces the number of possible mistakes in the initial stages. Previous activities can be participation in startup activities, volunteering, participation in nongovernmental organizations or participation in previous innovation activities (3).

$>$ Sustainability: implementing the right action is hardly enough for a successful social innovation process; long-term sustainability is the key for improving the quality of life. Financial support is temporary in most cases, so the process should become self-supplying in order to sustain it (4).

$>$ Replicability: successful actions can be good practices if the realization of process is reproducible. Because of the singularity of each action, all circumstances cannot be repeated, therefore it is worth analysing the necessary conditions for possible further actions in different places (5). 
Social learning: the learning process is presented in every stage of the social innovation process. Knowledge sharing can happen between implementers and participants in all contexts. In initial stages extending the available knowledge and transferring it are necessary for integration in the process. Internalisation of knowledge is one of the high priority actions. Lack of knowledge can be one of the most critical risk factors during the whole process (6).

$>$ Financial resources: one of the most critical points in the implementation process. Community contributions and searching for funding opportunities can contribute to gain the opportunity for success. Grant applications and cross-border support also can be options, but the most effective way is self-financing (7).

> Communication: the basis for knowledge sharing. Communication can be accomplished in person or using ICT tools, the main determinant is that there are regular opportunities. The top-down and bottom-up approaches are equally important, and the lack of either can lead to an inadequate response to needs. Integrating the underprivileged people from the communication point of view should be a priority during the social innovation process (8).

$>$ Non-financial resources: financial resources are considered one of the most critical points of the action, but without humans, ideas and recognizing the advantage of local abilities, the process of social innovation will take a long time and be difficult to sustain (9).

$>$ Leader, innovator: a person, group, or organization who helps to hold together the whole process, involving and encouraging people to take actions step by step for improving the quality of life (10).

$>$ Infrastructure: in a small town the implementation of innovation practice affects the small community within it. Effective implementation and results require the consideration of local abilities. In this level the supportive attitude of local government is essential to involve individuals. In addition, the state of development of existing infrastructure is a leading question in choosing the proper activity (11).

> Applied techniques: it is necessary to analyse the impact, sustainability and optimal functioning of tools, techniques and technology used in the process. Implementation often requires the use of machines, equipment, and other tools; knowledge is essential for their usage (12).

$>$ Expectations: some of the expectations come from the regulatory environment, the indicators required by subsidies and grants such as maintenance time, employment, and utilization rate, other expectations come from participants and are related to concrete applicability and improvement of well-being. If the results of the social innovation are unable to reach the expected level, its long-term sustainability will be at risk (13).

$>$ Novelty: new or novel practices are implemented when the activity has not been conducted elsewhere. If the same conditions are not available, necessary to consider the possibility of fulfilment of other conditions and modifications of practice (14).

$>$ Networks: during the implementation process of social innovation activity, different types of relationships are formed, and this network supports long-term sustainability and knowledge sharing. Networking is possible in a supply chain, which involves not only the direct supplier and buyer; investigating the entire chain and supporting contact with stakeholders can be crucial during establishing further partnerships. In addition, the community can be developed into a network involving small community, residence of township and other participants such as foundations. Cumulative knowledge is created in the network which can be used for further activities (15).

Each success factor is mentioned in several sources. Table 1 summarizes the literature review. 
Table 1

Success factors for social innovation process

\begin{tabular}{|l|c|c|c|c|c|c|c|c|c|c|c|c|c|c|c|}
\hline & $(1)$ & (2) & (3) & (4) & (5) & (6) & (7) & (8) & (9) & (10) & (11) & (12) & (13) & (14) & (15) \\
\hline Dziallas \& Blind (2019) & & $\checkmark$ & & & & $\checkmark$ & $\checkmark$ & & & & & & & & $\checkmark$ \\
\hline $\begin{array}{l}\text { Carvache-Franco et al. } \\
\text { (2018) }\end{array}$ & $\checkmark$ & $\checkmark$ & & $\checkmark$ & $\checkmark$ & $\checkmark$ & & & & & & & & & \\
\hline Rodriguez et al. (2018) & & & & & & $\checkmark$ & & & & $\checkmark$ & & $\checkmark$ & & & \\
\hline Wilde et al. (2018) & $\checkmark$ & & & $\checkmark$ & $\checkmark$ & & $\checkmark$ & & $\checkmark$ & $\checkmark$ & & & & $\checkmark$ & $\checkmark$ \\
\hline Neumeier (2017) & $\checkmark$ & $\checkmark$ & & & & $\checkmark$ & $\checkmark$ & $\checkmark$ & & & & & & & $\checkmark$ \\
\hline Repo \& Matschoss (2017) & $\checkmark$ & & & $\checkmark$ & & $\checkmark$ & $\checkmark$ & & $\checkmark$ & & & & & & \\
\hline Vasin et al. (2017) & $\checkmark$ & & & & & $\checkmark$ & & & & & $\checkmark$ & & & & $\checkmark$ \\
\hline Brandsen et al. (2016) & $\checkmark$ & & & $\checkmark$ & & & & & & & $\checkmark$ & & & & $\checkmark$ \\
\hline Unceta et al. (2016) & $\checkmark$ & & & & & $\checkmark$ & & & & & & & & & \\
\hline $\begin{array}{l}\text { Dainiené \& Dagiliené } \\
\text { (2015) }\end{array}$ & $\checkmark$ & & $\checkmark$ & & & $\checkmark$ & & & & & & & & & \\
\hline Dobele (2015) & $\checkmark$ & $\checkmark$ & & & & $\checkmark$ & & & & $\checkmark$ & & & & & \\
\hline Bekkers et al. (2013) & $\checkmark$ & $\checkmark$ & & & & $\checkmark$ & & & & $\checkmark$ & $\checkmark$ & & $\checkmark$ & $\checkmark$ & $\checkmark$ \\
\hline
\end{tabular}

Source: Own edition based on the references

Success factors are evaluated using different weights in each phase of the process- Their prioritization is not constant, everything depends on the time, the environment, the situation and many other factors influencing the social innovation action (Jooste \& Vlok 2015). Implementing the social innovation action means changes in routines that affect the whole community. For this reason, the implementing action should be carefully selected, reviewing the existence or developmental possibilities of critical factors.

\section{DECISION METHOD FOR EVALUATING THE INFLUENCING FACTORS}

Applying multi-criteria decision-making methods is significant in every aspect of life. However, complicated procedures are less well known. Making a decision is made more difficult by the number of variants, the existence of objective and subjective criteria, inconsistencies, etc. For this reason, several decision supports methods have been developed, but one single adequate method cannot be applied in all cases; choosing the possible right method is influenced by many criteria, situation and the individual decision maker. Multi-Attribute Utility Theory and
Outranking relations are the two main lines of multicriteria decision techniques. Applying Multi-Attribute Utility Theory means the aggregation of criteria into a function, and the examination of mathematical conditions of aggregation by maximization of the function. The compensation between criteria is allowed by the theory of method, consequently the profit of one criterion compensates for the loss of another (Pratt et al. 1976). In Outranking relation an alternative comes forward in preference order if it is at least as good as the follower while there is no essential reason to disconfirm the statement (Bouyssou, 1996). Based on the preference of the decision maker, multi-criteria decision-making method can be selected to determine the importance of success factors and its preference order.

The techniques that can be used during the social innovation process are limited by reason of variety of social innovation problems and range of available data. Different approaches are needed in each phase of the process for exploiting the social knowledge and supporting individual decision-making. The basis of choosing the appropriate method is provided by the complexity of problem, range of participants and other influencing factors. Figure 1 illustrates a non-comprehensive range of decision support methods that can be used during the process of social innovation. 


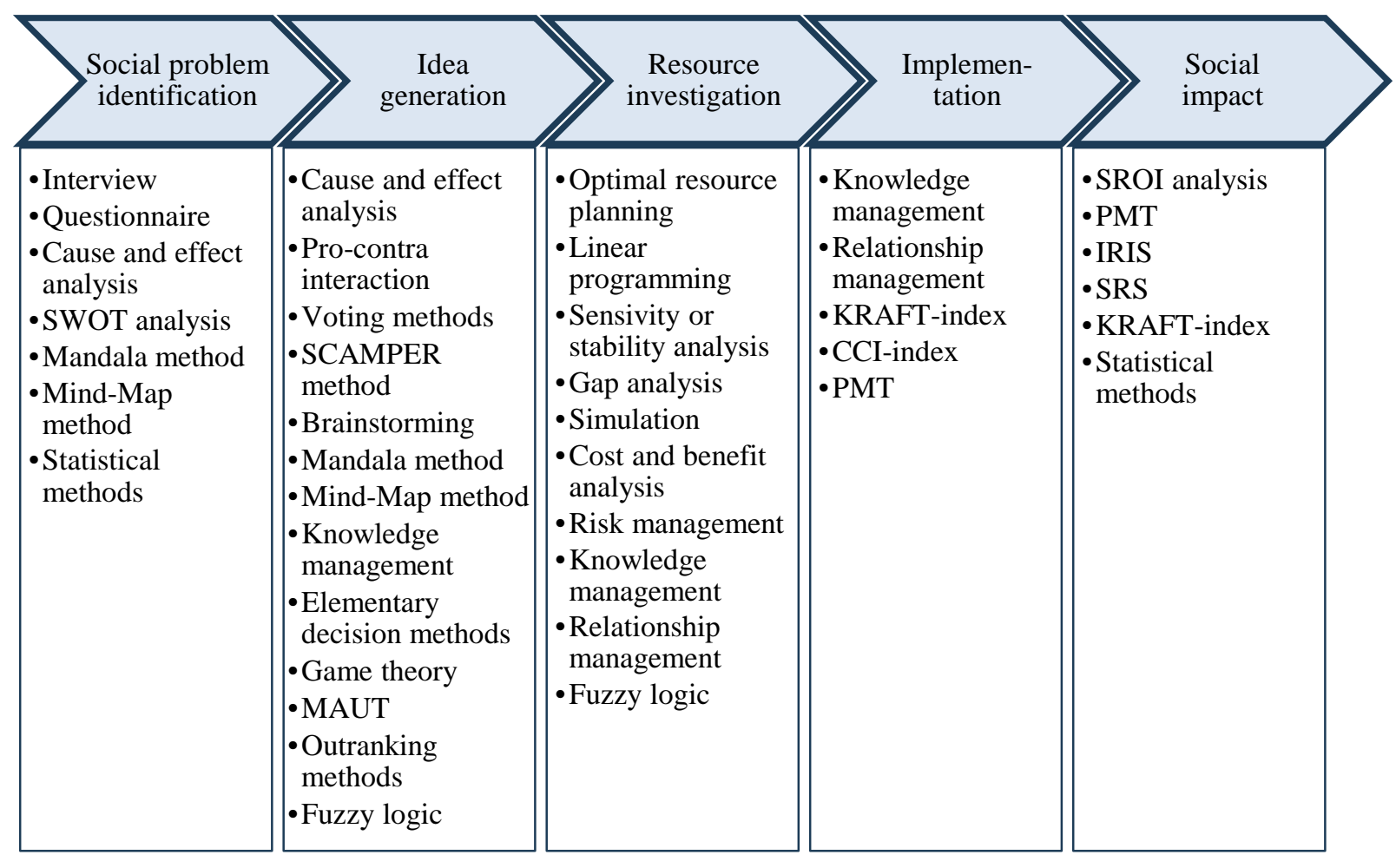

Source: Own edition

Figure 1. Possible decision support methods for the social innovation process

The process of social innovation can be supported and its impact can be measured with a properly chosen method. Both qualitative and quantitative information are required for social innovation related decisions, though making a constant priority order among influencing factors is impossible, and for this reason a procedure is needed to manage priorities involving non-numerical correlation in the evaluation.

In this paper a simple ranking method is used to analyse the success factors. The goal is to determine the importance of success factors from the perspective of decision-makers by means of hierarchization. The clarity is provided by representing the success factors in a hierarchical structure. The success factors are at the top of the hierarchy, categorization occurs in three categories at the second level: internal factors, external factors, and functional factors. The third level shows the classified success factors (Figure 2). 


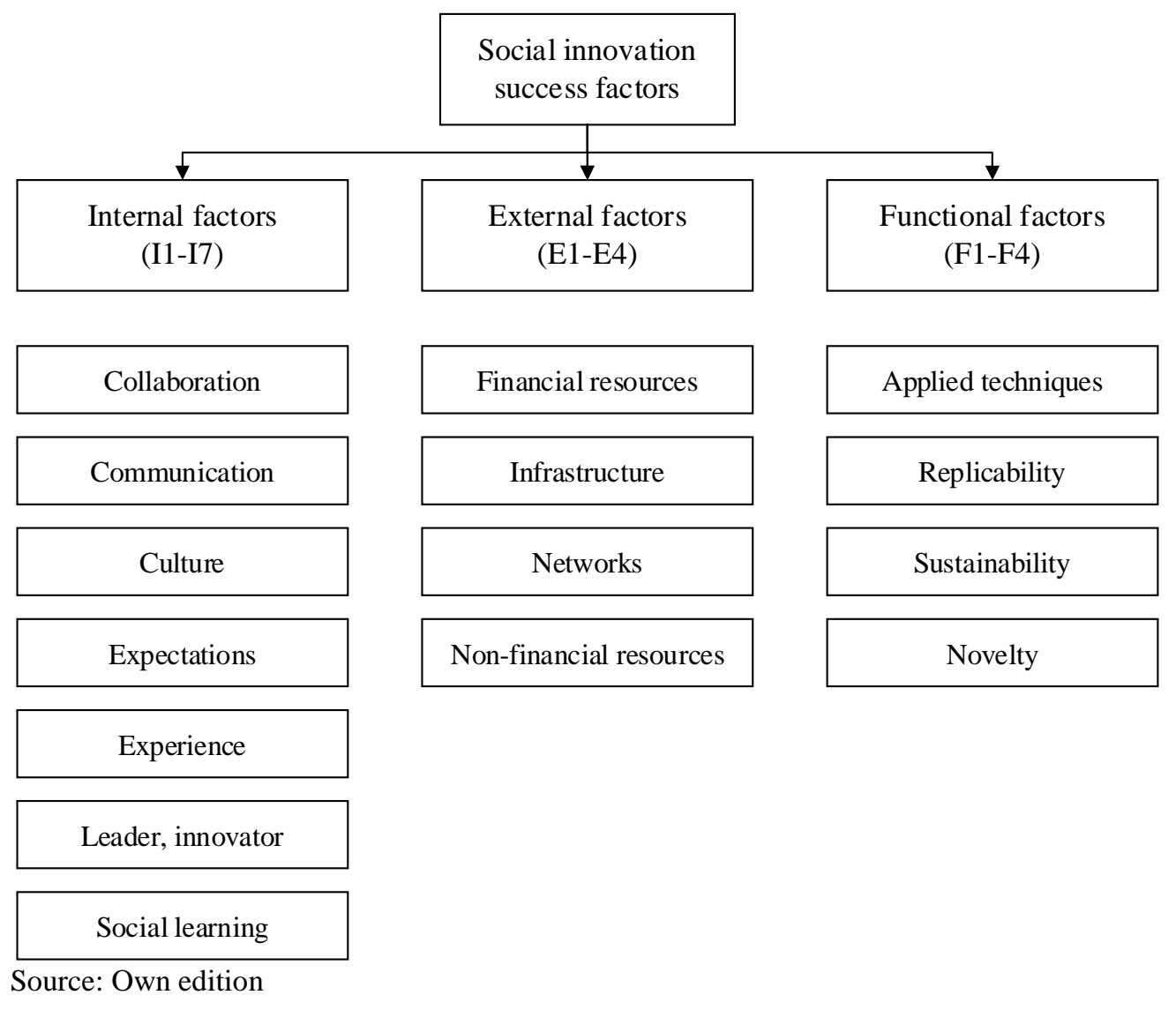

Figure 2. Hierarchy model of success factors

Doing pairwise comparisons and calculating factor weights are the next steps. This phase consists of three steps: determining the relative importance of the factors by pairwise comparisons, determining weight vectors, and determining the consistency.

The pairwise comparisons were done in individual structured interviews, categorizing the interviewees into four categories: individual as innovator (I), local government as innovator (L), foundation as innovator (F), organization as innovator (O). The scale developed by Saaty (1977) provided the values 1-9 for the comparison. The participants had to indicate the preferred factor from pairs and determine its importance with a number from a scale, where the minimum (1) means equally important and maximum (9) means the most important factor. The result matrix shows the relative preference of each factor based on Formula 1.

$$
a_{i j}=\frac{w_{i}}{w_{j}},
$$

where $a_{i j}$ is the $j$. element of matrix in line $i$. The expression is equal to the quotient of two values from a pairwise comparison, consequently it shows that factor importance $i$ against factor $j$. The matrix is come directly from the pairwise comparisons as in Formula 2.

$$
\left[\begin{array}{ccc}
1 & \cdots & a_{i j} \\
\vdots & 1 & \vdots \\
\frac{1}{a_{i j}} & \cdots & 1
\end{array}\right]
$$

The relative importance of factors is represented by the elements of the matrix.

Determining the consistency ratio (CR) is required to measure consistency. If the value of CR converges to zero, the consistency is presumable.

$$
\mathrm{CR}=\frac{\mathrm{CI}}{\mathrm{RI}},
$$

where the consistency ratio is equal to the quotient of the consistency index (CI) and the empirical average of consistency index (RI). Its value is considered satisfactory if it is not greater than 0.1. Eliminating inconsistency does not have to be the goal of decisions as it is not a sufficient condition for making good decisions. Furthermore, the value 0.1 is an empirical limit and it can be varied depending on the decision situation. 
Table 2

Weight vectors

\begin{tabular}{|c|c|c|}
\hline $\begin{array}{l}\text { Internal factors } \\
\text { (I1-I7) }\end{array}$ & $\begin{array}{l}\text { External factors } \\
\text { (E1-E4) }\end{array}$ & $\begin{array}{l}\text { Functional factors } \\
\text { (F1-F4) }\end{array}$ \\
\hline $\mathbf{w}_{I}^{\mathbf{T}}=\left[\begin{array}{lllllll}0.27 & 0.25 & 0.13 & 0.11 & 0.19 & 0.03 & 0.02\end{array}\right]$ & $\mathbf{w}_{I}^{\mathbf{T}}=\left[\begin{array}{llll}0.51 & 0.14 & 0.09 & 0.26\end{array}\right]$ & $\mathbf{w}_{I}^{\mathbf{T}}=\left[\begin{array}{llll}0.32 & 0.12 & 0.28 & 0.22\end{array}\right]$ \\
\hline $\mathbf{w}_{L}^{\mathbf{T}}=\left[\begin{array}{lllllll}0.15 & 0.10 & 0.09 & 0.18 & 0.32 & 0.11 & 0.05\end{array}\right]$ & $\mathbf{w}_{L}^{\mathrm{T}}=\left[\begin{array}{llll}0.67 & 0.11 & 0.04 & 0.18\end{array}\right]$ & $\mathbf{w}_{L}^{\mathbf{T}}=\left[\begin{array}{llll}0.27 & 0.08 & 0.49 & 0.16\end{array}\right]$ \\
\hline $\mathbf{w}_{F}^{\mathbf{T}}=\left[\begin{array}{lllllll}0.28 & 0.24 & 0.23 & 0.03 & 0.02 & 0.02 & 0.18\end{array}\right]$ & $\mathbf{w}_{F}^{\mathbf{T}}=\left[\begin{array}{llll}0.36 & 0.20 & 0.32 & 0.12\end{array}\right]$ & $\mathbf{w}_{F}^{\mathbf{T}}=\left[\begin{array}{llll}0.22 & 0.23 & 0.41 & 0.06\end{array}\right]$ \\
\hline $\mathbf{w}_{\boldsymbol{O}}^{\mathbf{T}}=\left[\begin{array}{lllllll}0.11 & 0.04 & 0.01 & 0.07 & 0.40 & 0.23 & 0.14\end{array}\right]$ & $\mathbf{w}_{\boldsymbol{o}}^{\mathbf{T}}=\left[\begin{array}{llll}0.38 & 0.05 & 0.47 & 0.10\end{array}\right]$ & $\mathbf{w}_{\boldsymbol{o}}^{\mathrm{T}}=\left[\begin{array}{llll}0.35 & 0.14 & 0.15 & 0.36\end{array}\right]$ \\
\hline
\end{tabular}

Source: Own edition

\section{RESULTS}

Four people participated in the study, one from each specified group (individual as innovator, local government as innovator, foundation as innovator, organization as innovator). Due to the limited number of responses, the paper is merely illustrative of the preferences of individuals at different levels of involvement.

The consistency ratio is appropriate for the external and functional factors, the values are less than $0.1\left(\mathrm{CR}_{\mathrm{E}}\right.$ equal to 0.074 and $\mathrm{CR}_{\mathrm{F}}$ equal to 0.092), but higher for the internal factors $\left(\mathrm{CR}_{\mathrm{I}}\right.$ equal to 0.185$)$. The absence of mind or lack of experience of participants can be the reason, but the final results are unaffected by its value, during a pilot check - some of the data was filtered to reduce inconsistency - no significant influence on the final order was detected.

Based on the result of pairwise comparisons done by participants, the values of normalized matrices can be determined and their weight vectors can be calculated. The elements of weight vectors can be calculated with Formula 4.

$$
\mathbf{w}=\frac{\sum_{i=1}^{n} a_{n_{i}}}{\sum_{i, j=1}^{n} a_{n_{i j}}},
$$

where the elements of weight vector $\mathrm{w}$ are defined as the quotient of aggregated sum of rows of the normalized matrix and sum of the elements in the whole matrix. Table 2 illustrates the weight vectors for the three categories.
The ranking of factors within categories is determined based on the calculated weight vectors (Table 3). In internal factors collaboration was the most cited success factor, ranked in the first place by the valuation of individual and foundation based on the weights $(0.27$ and 0.28), but for the local government and organization experience was the most important, which is one of the less cited factors. In almost all cases the individual and foundation had similar valuations, factors which connected to cooperation and participation are the most important. Factors which help in the implementation such as experience (0.32 and 0.40) and leader, innovator (0.11 and 0.23 ) were preferred by the representative of the local government and the organization. In external factors financial resources are in the first place for individual (0.51), local government (0.67) and foundation (0.38), but for the organization networks (0.47) were considered the most important. The importance of financial elements was expected, in small communities the most challenging task is putting up the necessary financial background for the action. Different judgments are eventuated in the functional factors. For the local government and foundation, the sustainability was the first (0.49 and 0.41), while the most important factor for the individual was the applied techniques (0.32) and for the organization it was the novelty (0.36). The factors that can help the practical implementation are the priority for organizations, while cohesion is top for the individual and foundation, and the exploitation of available opportunities is most important to the local government. 
Table 3

Rank of success factors

\begin{tabular}{|c|c|c|c|c|c|}
\hline \multirow{2}{*}{ Category } & \multirow{2}{*}{ Success factor } & \multicolumn{4}{|c|}{ Rank } \\
\hline & & $\mathbf{I}$ & $\mathbf{L}$ & $\mathbf{F}$ & $\mathbf{O}$ \\
\hline \multirow{7}{*}{$\begin{array}{l}\text { Internal factors } \\
\text { (I1-I7) }\end{array}$} & Collaboration & 1 & 3 & 1 & 4 \\
\hline & Communication & 2 & 5 & 2 & 6 \\
\hline & Culture & 4 & 6 & 3 & 7 \\
\hline & Expectations & 5 & 2 & 5 & 5 \\
\hline & Experience & 3 & 1 & 6 & 1 \\
\hline & Leader, innovator & 6 & 4 & 6 & 2 \\
\hline & Social learning & 7 & 7 & 4 & 3 \\
\hline \multirow{4}{*}{$\begin{array}{l}\text { External factors } \\
\text { (E1-E4) }\end{array}$} & Financial resources & 1 & 1 & 1 & 2 \\
\hline & Infrastructure & 3 & 3 & 3 & 4 \\
\hline & Networks & 4 & 4 & 2 & 1 \\
\hline & Non-financial resources & 2 & 2 & 4 & 3 \\
\hline \multirow{4}{*}{$\begin{array}{l}\text { Functional factors } \\
\text { (F1-F4) }\end{array}$} & Applied techniques & 1 & 2 & 3 & 2 \\
\hline & Replicability & 4 & 4 & 2 & 4 \\
\hline & Sustainability & 2 & 1 & 1 & 3 \\
\hline & Novelty & 3 & 3 & 4 & 1 \\
\hline
\end{tabular}

Source: Own edition

Significant difference can be discovered between the priority rank of the individual, foundation, local government and organization. Kendall's coefficient of concordance was calculated (Formula 5) for testing the rate of accordance adding correction factor for the adjustment of distortional effect (tied values):

$$
\mathrm{W}=\frac{\Delta}{\Delta_{\max }}=\frac{\Delta}{\frac{1}{12} * \mathrm{k}^{2} *\left(\mathrm{n}^{3}-\mathrm{n}\right)-\mathrm{k} * \sum_{\mathrm{L}} \mathrm{L}},
$$

where Kendall's coefficient of concordance is equal to the quotient of $\Delta$ quadratic variation and $\Delta_{\max }$ adjusted by maximum correction factor (it shows the $100 \%$ correlation). $\mathrm{W}$ is equal to 1 in the case of full agreement, and $\mathrm{W}$ is equal to zero if ranks show contrast. Table 4 shows the calculated coefficient values.

The $\mathrm{W}$ significance test is necessary to determine the correlation between the ranks. The fundamental assumption is the lack of agreement among the participants, therefore $\mathrm{W}$ greater than zero refers to a random effect, while the alternative hypothesis assumes agreement between participants. Significance test is possible to achieve with the value of $\chi 2$ distribution (Formula 6.) and its comparison to the threshold.

$$
\chi^{2}=\mathrm{k} *(\mathrm{n}-1) * \mathrm{~W},
$$

where the value of distribution is equal to the value of multiplication of number of evaluation factors $(\mathrm{k})$, degree of freedom (DF equal to n-1) and coefficient of concordance.

The calculated coefficient of concordance and values of $\chi 2$ distribution are presented in Table 4. The critical value of $\chi 2$ at $1 \%$ significant level is 16.8 for internal ( $\mathrm{k}$ equal to 4 and DF equal to 6) and 11.3 for external and functional actors (k equal to 4 and DF equal to 3 ). The concrete values of $\chi 2$ are always lower than the critical values, this involves the acceptance of the $\mathrm{H}_{0}$ hypothesis, the $\mathrm{W}$ greater than zero values refer to random effect, the highest value of $\chi 2$ is less than half of its critical value.

Lack of concordance can be a problem during common activity. The social innovation process would be managed with different approaches and priorities being set between activities, which can inhibit the effectiveness of collective work. Increasing the concordance among the involved participants is essential from the beginning of the process. 
Table 4

Coefficient of concordance

\begin{tabular}{|c|c|c|c|}
\hline Category & Success factor & $\begin{array}{c}\text { Coefficient of } \\
\text { concordance (W) }\end{array}$ & Value of $\chi^{2}$ \\
\hline $\begin{array}{l}\text { Internal factors } \\
\text { (I1-I7) }\end{array}$ & $\begin{array}{l}\text { Collaboration } \\
\text { Communication } \\
\text { Culture } \\
\text { Expectations } \\
\text { Experience } \\
\text { Leader, innovator } \\
\text { Social learning }\end{array}$ & $\begin{array}{l}0.110 \\
0.002 \\
0.036 \\
0.002 \\
0.056 \\
0.009 \\
0.056\end{array}$ & $\begin{array}{l}2.649 \\
0.054 \\
0.857 \\
0.054 \\
1.351 \\
0.216 \\
1.351\end{array}$ \\
\hline $\begin{array}{l}\text { External factors } \\
\text { (E1-E4) }\end{array}$ & $\begin{array}{l}\text { Financial resources } \\
\text { Infrastructure } \\
\text { Networks } \\
\text { Non-financial resources }\end{array}$ & $\begin{array}{l}0.446 \\
0.161 \\
0.013 \\
0.013\end{array}$ & $\begin{array}{l}5.357 \\
1.929 \\
0.158 \\
0.158\end{array}$ \\
\hline $\begin{array}{l}\text { Functional factors } \\
\text { (F1-F4) }\end{array}$ & $\begin{array}{l}\text { Applied techniques } \\
\text { Replicability } \\
\text { Sustainability } \\
\text { Novelty }\end{array}$ & $\begin{array}{l}0.053 \\
0.286 \\
0.118 \\
0.013\end{array}$ & $\begin{array}{l}0.632 \\
3.429 \\
1.421 \\
0.158\end{array}$ \\
\hline
\end{tabular}

Source: Own edition

\section{EVALUATION}

Choosing the appropriate method helps us to understand the nature and needs of participants and the process of social innovation. Different phases of the process require different tools and techniques to support the implementation. Success factors must be considered during the whole process; this is essential to attain the expected result. In this study data were provided for the comparison of success factors by four participants. The comparisons were performed with the method of pairwise comparison, which gives easier structure and is more manageable for the participants. After the comparisons are done, weight vectors can be calculated to show the importance of the factors, which gives the basis of the ranking. It was expected that different type of factors will be more important for the innovators at various levels of involvement.

Financial resources were highlighted during the entire process. This external factor received the highest values of the weights, except for the organization, where the networks factor was the most important. This information shows the priority and thinking of participants. Social innovation requires cooperation during the process and the lack of supporting attitude can lead the essence of it in the wrong direction. In this case the weights are wellbalanced, just the financial factor indicates highlighted priority, which shows the necessity of financial elements for the implementation according to the innovators.

In most cases a group or community works together during the innovation process. Participants often come from different fields of action with various experiences and decision levels. Mutual understanding and accordance are needed for effective work. If the priority of participants is diverse, the social aspect becomes de-emphasized. The calculated $\mathrm{W}$ values show the low rate of accordance in this case, and the significance level confirms the assumption of theH0 hypothesis, the predominance of random effect. Participants are recommended to increase the level of accordance before the main steps and decisions in the process, otherwise different ideas can decrease the efficiency of social innovation action.

\section{CONCLUSION}

Using different tools and decision support techniques at each phase of the social innovation process is needed to explore possibilities and choose the right option. Exploring available resources and future opportunities is essential for proper evaluation. A flexibly developed decision support system is needed to support each step of the process. Involving the participants is essential for using common knowledge during the process; its formation has to respect their concepts about increasing the quality of life. Knowing the influencing factors of social innovation helps to identify the critical points of the process and plan the right actions for manage them.

Prioritizing the success factors related to social innovation by participants' point of view was adequately assisted by using a ranking method based on pairwise comparisons. However, there are limitations and the preconditions should be known for proper use of these results:

$>$ The sample is not representative.

$>$ Lack of information can affect the final rank.

$>$ The absence of mind or lack of experience of participants can provide misleading results.

> The real world is often inconsistent. 
Potential reluctance to use the method because of the time it takes and its heavily mathematical background.

\section{Acknowledgement}

This research was supported by the project no. EFOP-3.6.2-16-2017-00007, titled Aspects on the development of intelligent, sustainable and inclusive society: social, technological, innovation networks in employment and digital economy. The project has been supported by the European Union, co-financed by the European Social Fund and the budget of Hungary.

\section{REFERENCES}

ANAND, G., WARD, P. T., TATIKONDA, M. V. \& SCHILlinG, D. A. (2009): Dynamic capabilities through continuous improvement infrastructure. Journal of Operations Management, 27. (6), pp. 444-461. https://doi.org/10.1016/j.jom.2009.02.002

ANGELIDOU, M. \& PSALTOGLOU, A. (2017): An empirical investigation of social innovation initiatives for sustainable urban development. Sustainable Cities and Society, 33 (1), pp. 113-125. https://doi.org/10.1016/j.scs.2017.05.016

BEKKERS, V. J. J. M., TUMMERS, L. G., STUIJFZAND, B. G. \& VOORBERG, W. (2013): Social Innovation in the Public Sector: An integrative framework. LIPSE Working papers (no. 1). Rotterdam: Erasmus University Rotterdam.

BOUYSSOU, D. (1996): Outranking Relations: Do They Have Special Properties? Journal of Multi-Criteria Decision Analysis, 5 (2), pp. 99-111. https://doi.org/10.1002/(sici)1099-1360(199606)5:2<99::aid-mcda97>3.0.co;2-8

BRANDSEN, T., ECCHIA, G., ESCHWEILER, J., HULGÅRD, L. \& NOGALES, R. (2016): Co-creating a Social Innovation Research Agenda for Europe, Social Innovation Europe/EMES Network [Online].

Available at: https://webgate.ec.europa.eu/socialinnovationeurope/en/magazine/methods-and-tools/specialfeatures/co-creating-social-innovation-research-agenda-europe [Retrieved: 01 December 2019]

CARVACHE-FRANCO, O. D., GUTIERREZ, G. \& BARRENO, E. Z. (2018): The Key Factors in Social Innovation Projects. Mediterranean Journal of Social Sciences, 9 (5), pp. 107-116. https://doi.org/10.2478/mjss-2018-0142

DAINIENÉ, R. \& DAGILIENÉ, L. (2015): A TBL Approach Based Theoretical Framework for Measuring Social Innovations. Procedia - Social and Behavioral Sciences, 213, pp. 275-280. https://doi.org/10.1016/j.sbspro.2015.11.537

DOBELE, L. (2015): Factors which influence the development of social innovation in Latvia. Proceedings of the 2015 International Conference "Economic Science for Rural Development” (No. 40), Jelgava, LLU ESAF, pp. 226-238.

DZIALLAS, M. \& BLIND, K. (2019): Innovation indicators throughout the innovation process: An extensive literature analysis. Technovation, 80-81, pp. 3-29. https://doi.org/10.1016/j.technovation.2018.05.005

EDWARDS-SCHACHTER, M. \& WALLACE, M. L. (2017): 'Shaken, but not stirred': Sixty years of defining social innovation. Technological Forecasting and Social Change, 119, pp. 64-79. https://doi.org/10.1016/j.techfore.2017.03.012

JOOSTE, J. L. \& VLOK, P. J. (2015): A decision support model to determine the critical success factors of asset management services. South African Journal of Industrial Engineering, 26 (1), pp. 27-43. https://doi.org/10.7166/261-1043

KADERABKOVA, A. \& SAMAN, S. M. (2013): Evaluations of social innovations: their characteristics and impacts, cross country comparisons and implications for policy support. Social Frontiers: The next edge of social innovation research, at GCU's Conference [Online], London Campus, 17 p. Available at:

http://www.transitsocialinnovation.eu/content/original/Book\%20covers/Local\%20PDFs/101\%20SF\%20Kaderabkov a\%20and\%20Saman\%20Evaluation\%20of\%20SI\%20cross\%20country\%20comparisons\%202013.pdf [Retrieved: 18 December 2019]

KOCZISZKY, GY., VERESNÉ SOMOSI, M. \& BALATON, K. (2017): A társadalmi innováció vizsgálatának tapasztalatai és fejlesztési lehetöségei. [Experiences and opportunities for developing social innovation] Vezetéstudomány - Budapest Management Review, 48 (6-7), pp. 15-19. https://doi.org/10.14267/veztud.2017.06.02 
METSZOSY, G. (2019): Investigating the Process of Social Innovation - A Social Learning Based Approach. In: Nemec, Radek; Chytilova, Lucie (eds.) Proceedings of the 13th International Conference on Strategic Management and its Support by Information Systems 2019: (SMSIS 2019), Ostrava, Czech Republic: VSB-Technical University of Ostrava, (2019) pp. 51-59.

MISURACA, G. \& PASI, G. (2019): Landscaping digital social innovation in the EU: Structuring the evidence and nurturing the science and policy debate towards a renewed agenda for social change. Government Information Quarterly, 36 (3), pp. 592-600. https://doi.org/10.1016/j.giq.2019.02.004

MURRAY, R., CAULIER-GRICE, J. \& MULGAN, G. (2010): The open book of social innovation, The Social Innovator Series [Online], London: NESTA.

Available at: https:/youngfoundation.org/wp-content/uploads/2012/10/The-Open-Book-of-Social-Innovationg.pdf [Retrieved: 27 December 2019]

NEUMEIER, S. (2017): Social innovation in rural development: identifying the key factors of success. The Geographical Journal, 183 (1), pp. 34-46. https://doi.org/10.1111/geoj.12180

POL, E. \& VILLE, S. (2009): Social innovation: Buzz word or enduring term? Journal of Socio-Economics, 38 (6), pp. 878-885. https://doi.org/10.1016/j.socec.2009.02.011

PRATT, J. W., RAIFFA, H. \& SCHLAIFER, R. (1976): Foundations of Decision Under Uncertainty: An Elementary Exposition. Readings in Material Economics, pp. 15-30. https://doi.org/10.1016/b978-0-08-019605-3.50009-2

RAJAPATHIRANA, J. \& HUI, Y. (2018): Relationship between innovation capability, innovation type, and firm performance. Journal of Innovation \& Knowledge, 3 (1), pp. 44-55. https://doi.org/10.1016/j.jik.2017.06.002

REPO, J. P \& MATSCHOSS, K. J. (2017): Social Innovation in Focus: Comparison of Types of Success Factors. In Bitran, I., Conn, S., Huizing, K. R. E., Torkkeli, M. \& Tynnhammar, M. (eds), The XXVIII ISPIM Innovation Conference: Composing the Innovation Symphony, Austria, Vienna on 18-21 June 2017. International Society for Professional Innovation Management.

ROCKART, J. F. (1979): Chief executive define their own data needs. Harvard Business Review, 57 (1), pp. 81-93.

RODRIGUEZ, E. L., SUGAHARA, C. R., CAVAHO DE BENEDICTO, S. \& LOMBARDO FERREIRA, H. (2018): Determinant Factors of Social Innovation Capability in Nonprofit Organizations and Social Businesses. International Journal for Innovation Education and Research, 6 (12), pp. 91-119. https://doi.org/10.31686/ijier.vol6.iss12.1254

SAAD, M. (2004): Issues and challenges arising from the application of innovation strategies based on the triple helix culture. International Journal of Technology Management \& Sustainable Development. 3 (1), pp. 17-34. https://doi.org/10.1386/ijtm.3.1.17/0

SAATY, T. L. (1977): A scaling method for priorities in hierarchical structures. Journal of Mathematical Psychology, 15 (3), pp. 234-281. https://doi.org/10.1016/0022-2496(77)90033-5

SANDERS, B., MULGAN, G., ALI, R. \& TUCKER, S. (2007): Social Innovation: What It Is, Why It Matters and How It Can Be Accelerated [Online]. The Young Foundation, Working Paper. Available at: https://youngfoundation.org/wp-content/uploads/2012/10/Social-Innovation-what-it-is-why-it-matters-how-it-canbe-accelerated-March-2007.pdf [Retrieved: 27 December 2019.]

SHANTZ, K. (2015): A new definition of social innovation. Centre for Social Innovation [Online]. Available at: https://socialinnovation.org/a-new-definition-of-social-innovation/ [Retrieved: 29 December 2019.]

SIMMS, J. R. (2006): Technical and social innovation determinants of behaviour. Systems Research and Behavioral Science, 23 (3), pp. 383-393. https://doi.org/10.1002/sres.734

SOMA, K., VAN DEN BURG, S. W. K., HOEFNAGEL, E. W. J., STUIVER, M. \& VAN DER HEIDE, M. (2018): Social innovation - A future pathway for Blue growth? Marine Policy, 87, pp. 363-370. https://doi.org/10.1016/j.marpol.2017.10.008

TOHIDI, H. \& JABBARI, M. M. (2012): The Effective Factors on Formation of Innovation Processes. Procedia Technology, 1, pp. 524-527. https://doi.org/10.1016/j.protcy.2012.02.113

UNCETA, A., CASTRO-SPILA, J. \& GARCIA-FRONTI, J. (2016): Social innovation indicators. Innovation: The European Journal of Social Science Research, 29 (2), pp. 192-204. https://doi.org/10.1080/13511610.2015.1127137

VASIN, S. M., GAMIDULlAEVA, L. A. \& ROSTOVSKAYA, T. K. (2017): The Challenge of Social Innovation: Approaches and Key Mechanisms of Development. European Research Studies Journal, XX (2B), pp. 25-45. https://doi.org/10.35808/ersj/664

WILDE, R. SHIMONI, R., LEGASPI, A., HENWOOD, S., BROWN, A. \& LOBLAW, T. (2018): Social Innovation on the Ground: Accessible and Evidence-Based Tools for Social Innovators. Final Project Report, BowValley College, Research\&Innovation, p. 120. [Online] Available at: https://bowvalleycollege.ca/-/media/bvc/home/teaching-andresearch/aiar/social-innovation-on-the-ground/002_social-innovation-on-the-ground-final-projectreport.ashx?la=en\&hash=66A01EDE806AF9895D03841E365ECC2485003B1C [Retrieved: 29 December 2019.]

ZAPF, W. (1991): The role of innovations in modernization theory. International Review of Sociology, 2 (3), pp. 83-94. https://doi.org/10.1080/03906701.1991.9971098 